\title{
Empirical challenges in the use of learning curves for assessing the economic prospects of renewable energy technologies ${ }^{\text {th }}$
}

\author{
Patrik Söderholm ${ }^{\mathrm{a}, *}$, Thomas Sundqvist ${ }^{\mathrm{b}}$ \\ ${ }^{a}$ Division of Social Sciences, Lulea University of Technology, Economics Unit, 97187 Lulea, Sweden \\ ${ }^{\mathrm{b}}$ Swedish Competition Authority, 10385 Stockholm, Sweden
}

Received 30 January 2006; accepted 15 December 2006

Available online 1 March 2007

\begin{abstract}
In bottom-up energy models endogenous technical change is introduced by implementing technology learning rates, which specify the quantitative relationship between the cumulative experiences of the technology on the one hand and cost reductions on the other. The main purpose of this paper is to critically analyze the choice of modeling and estimation strategies in learning curve analyses of power generation costs. We identify and discuss a number of theoretical and econometric issues involved in the estimation of learning curves. These include the presence of omitted variable bias and simultaneity, but also methodological problems related to the operationalization of theoretical concepts (i.e., learning-bydoing) and the associated use of data. We illustrate the importance of these issues by employing panel data for wind power installations in four western European countries, which are used to compare the results from different learning curve model specifications. The results illustrate that the estimates of learning rates may differ significantly across different model specifications and econometric approaches. The paper ends by outlining a number of recommendations for energy model analysts, who need to select appropriate energy technology learning rates from the empirical literature, or who choose to perform the empirical work themselves.
\end{abstract}

(C) 2007 Elsevier Ltd. All rights reserved.

Keywords: Learning curve; Learning rate; Energy technology; Wind power; Econometrics; Europe

\footnotetext{
in Financial support from the Swedish Energy Agency (International Climate Policy Program) is gratefully acknowledged, as are helpful comments from William Nordhaus, an anonymous reviewer and seminar participants at the Environmentally Compatible Energy Strategies Project (ECS), the International Institute for Applied Systems Analysis (IIASA), Austria.

${ }^{*}$ Corresponding author. Fax: + 46920492035 .

E-mail addresses: patrik.soderholm@1tu.se (P. Söderholm), thomas.sundqvist@kkv.se (T. Sundqvist).
} 


\section{Introduction}

The introduction of learning curves for different energy technologies (primarily bottomup) energy system models has become increasingly common. The basic idea is that investments in new renewable energy technologies are more expensive than those in old technologies, but the costs of the former can be assumed to decrease with increases in their market share so that at some point they will become a more attractive choice than the old technologies, which are (it is often argued) more mature and experience fewer potentials for cost reductions [1]. ${ }^{1}$ Cost reductions are the result of learning-by-doing, i.e., performance improves as capacity and production expand. Learning curves are used to empirically quantify the impact of increased experience and learning on the cost of a given technology, and specify thus, for instance, the investment cost as a function of cumulative capacity. In this way one obtains an endogenous representation of technical change, and the implementation of learning curves in large-scale energy system models connects future cost developments to current investments in new technology in a way that the cost of the new technology will depend on earlier energy system developments. ${ }^{2}$

The introduction of learning in energy models may have important implications for the timing and the cost of environmental policies. High learning rates for new vs. old technologies support early, upfront investment in new technologies to reap the economic benefits of technological learning, and they also imply that the gross costs of climate policy may be comparatively low (e.g., [9]). Naturally, in the long-run differences in learning rates across technologies will also influence the mix of technologies in use. For instance, bottomup models of the power generation sector typically assume that learning rates for wind and solar power are higher than the corresponding rates for, say, coal and nuclear power. This means that-given the implementation of sufficient technology support policies - the generation share of the former can increase substantially over time even if their current costs are high. Rosendahl [10] even suggests that if learning rates differ across carbon dioxide reduction measures, carbon taxes should be differentiated according to these rates (at least as long as the learning effects possess public good features).

The above suggests that if energy models are to generate meaningful and policy-relevant results, reliable estimates of the learning rates are needed. However, it is probably fair to conclude that previous empirical studies of learning rates provide few uniform conclusions about the size of these rates. For instance, McDonald and Schrattenholzer [11] show that the learning rate for wind turbines range between $8 \%$ and $18 \%$ depending on study, and similar differences exist for other technologies. ${ }^{3}$ Given this, the recent research on moving away from deterministic learning estimates to the introduction of uncertainties in the

\footnotetext{
${ }^{1}$ Still, McVeigh et al. [2] show that even though the costs of renewable energy technologies in the past have fallen far beyond expectations, they have often failed to meet expectations with respect to market penetration. This suggests that the costs of the traditional power sources have fallen as well and apart from cost disadvantages there exist additional legislative and institutional obstacles to increased renewable energy diffusion.

${ }^{2}$ The energy system models that incorporate learning-by-doing for energy technologies typically have a bottomup structure, i.e., optimization models in which different technological options are explicitly specified. See, for instance, Messner [3], Mattsson and Wene [4], Kouvaritakis et al. [5], Barreto and Kypreos [6], and the survey article by Berglund and Söderholm [7]. Rasmussen [8] introduces learning-by-doing in a top-down (general equilibrium) model.

${ }^{3}$ See also Ibenholt [12], who analyzes the causes of variation in learning rate estimates for the wind power technology.
} 
distribution of future costs is welcome (e.g., [9]). However, in spite of this there exists a need to provide reliable mean estimates of learning rates.

The main purpose of this paper is to survey and critically analyze the choice of modeling and estimation strategies in learning curve analyses of energy technology costs. We hypothesize that differences in learning rates for a given technology are not only due to the use of differing datasets (with different variable definitions covering various time periods), but arise also as a result of the use of different model specifications and econometric techniques. This hypothesis is tested by comparing the results from different model specifications using the same panel dataset of wind power investment costs across four European countries over the time period 1986-2000. We conclude that the estimation of learning curves involves a number of important econometric, methodological and economic-theoretical issues that only rarely are acknowledged in previous work. While the specification of learning curve models have been discussed also in previous work (e.g., $[13,14])$, this paper differs from these earlier studies in that we identify a number of issues at the start and systematically investigate the consequences of acknowledging or ignoring these in the empirical analysis. For this reason the majority of the model estimations discussed employs an identical dataset (see Section 3 for details).

The paper proceeds as follows. In Section 2, starting from the traditional learning curve specification we introduce the theoretical and econometric topics to be addressed. Section 3 presents the data to be used in the empirical part of the paper and outlines some important model estimation issues, while Section 4 presents and discusses the empirical estimation results from different learning curve specifications for the European wind power sector. Finally, Section 5 provides some concluding remarks and implications.

\section{The economics and econometrics of learning curve analysis}

\subsection{The traditional learning curve model and associated econometric problems}

The simplest and - in energy technology studies - most commonly used specification of the learning curve (e.g., [15-17]) relates the cost of the technology to the cumulative capacity installed. For the wind power case the learning curve equation can be written as

$$
C_{n t}=\delta_{0} C C_{n t}^{\delta_{\mathrm{L}}},
$$

where $C C_{n t}$ is the chosen level of total installed wind power capacity in country $n(n=1, \ldots, N)$ for a given year $t(t=1, \ldots, T)$ used here as a proxy for learning. ${ }^{4} C_{n t}$ represents the real engineering unit cost (per $\mathrm{kW}$ ) of installing a windmill, i.e., all investment cost items, such as grid connection, foundations, and the cost of the turbine, and $\delta_{0}$ is the corresponding cost at unit cumulative capacity. By taking the logarithm of Eq. (1) one obtains a linear model, which can be estimated econometrically and an estimate of $\delta_{\mathrm{L}}$ can be obtained. We have

$$
\ln C_{n t}=\ln \delta_{0}+\delta_{\mathrm{L}} \ln C C_{n t}+\varepsilon_{n t},
$$

where $\varepsilon_{n t}$ is an additive disturbance term which is assumed to have a zero mean, constant variance, and to be independent and normally distributed. The learning-by-doing rate is

\footnotetext{
${ }^{4} \mathrm{We}$ assume here (fairly realistically) that the installed capacity equals the cumulative capacity (i.e., no windmills have been shut down during the time period under study).
} 
then defined as $1-2^{\delta_{\mathrm{L}}}$ (where $\delta_{\mathrm{L}}<0$ implies positive learning), and it shows the percentage change in cost due to a doubling of cumulative capacity. For instance, a learning rate of $14 \%$ implies that the cost is reduced to $86 \%$ of its previous level after a doubling of cumulative capacity. With this particular specification one assumes that the learning rate is equally high in the $N$ countries (although this assumption could easily be relaxed by either employing country-specific estimations or by introducing interactive slope-dummy variables for the learning parameter $\delta_{\mathrm{L}}$ ). Given the scope of this paper-the comparison of different model specifications using the same dataset-we do not pay particular attention to the presence of country-specific learning rates (see, however, [13]).

Recently researchers have extended this simple formulation of the learning curve by incorporating also, for instance, cumulative R\&D expenses directed towards wind power (e.g., [5]) or an R\&D-based knowledge stock (e.g., [18,19]) as additional explanatory variables. These latter specifications are commonly known as two-factor learning curves, and they produce also an estimate of the so-called learning-by-searching rate, which shows the impact on costs of a doubling in the R\&D-based variable. Incorporating such R\&D-based measures into bottom-up energy models permits an analysis of the optimal allocation of R\&D funds among competing technologies (e.g., [6]). The two-factor learning curve equation can thus be written as

$$
\ln C_{n t}=\ln \delta_{0}+\delta_{\mathrm{L}} \ln C C_{n t}+\delta_{K} \ln K_{n t},
$$

where $K_{n t}$ is the R\&D-based knowledge stock (defined in Section 2.2). The above two approaches are the most commonly used in previous studies aiming at empirically assessing technology learning rates in the energy sector.

We highlight four different issues that deserve attention when estimating learning curves using econometric techniques and that often are ignored in previous work. ${ }^{5}$ The first issue deals with the choice of dataset and definitions. Even though one relies on one specific dataset there exists a need to check for the effect of removing single observations, especially outliers that may greatly influence the learning rate estimate. It may also be the case that the learning rate varies over different time periods (e.g., [15]). In the empirical section we drop a few early observations and investigate how this affects the estimates of the learning rate. We also consider the impact of using different variable definitions. As has already been noted learning-by-searching can be captured by implementing different R\&D-based variables. Similarly, as a proxy for learning-by-doing one can also use cumulative production or other activity variables (in replacement of cumulative capacity).

Second, we pay particular attention to the way in which technology learning is operationalized. The choice of cumulative capacity as an indicator of learning-by-doing is of course not devoid of problems. Since this variable typically shows a strong increasing trend over time one may ask the question if cumulative capacity really captures the specific impact of learning-by-doing activities, or if it is just captures a general (exogenously given) technical progress. A similar argument could be made for the R\&D-based knowledge stock, which also tends to show a strong positive trend. One simple way of testing for this possibility is the inclusion of a time trend in the learning equation. The idea is that if the

\footnotetext{
${ }^{5} \mathrm{We}$ do not attempt here to provide an entirely comprehensive analysis of all possible econometric issues involved in the estimation of learning curves. For instance, we neither discuss explicitly the problem of multicollinearity (i.e., the presence of linear relationships among explanatory variables), and nor autocorrelation (i.e., the situation in which the successive values of the disturbance term are dependent). Still, the null hypothesis of no autocorrelation has been tested for all model specifications.
} 
learning coefficients are indeed picking up the learning activity impacts they should remain statistically significant also after a time trend has been added to the model. This test is performed in other studies (e.g., [20,21]), and some of these show that the impact of cumulative capacity on costs are very sensitive to the inclusion of a time trend in the traditional learning curve model. In contrast to these earlier studies we introduce a time trend in a large number of model specifications, something that, for instance, permits us to also investigate the robustness of learning-by-searching rates.

The third issue recognizes that the model specified in Eq. (1) assumes that the cumulative wind capacity is an exogenous (independent) variable. A windmill is not necessarily built because it is cheap and efficient, but rather it becomes cheap because it is built and operated. However, one principal reason for why wind generators invest in new capacity is because learning activities and $R \& D$ measures have brought down the costs of generating wind electricity. This suggests that both innovation and diffusion ought to be viewed as endogenous, i.e., they are simultaneously determined and should not be analyzed in isolation. ${ }^{6}$ Technically endogeneity implies that in the learning equation in Eq. (2) the regressor $C C_{n t}$ and the disturbance term $\varepsilon_{n t}$ are negatively correlated. This means that estimation by ordinary least squares (OLS) would yield biased and inconsistent estimates of $\delta_{\mathrm{L}}$ and thus of the learning-by-doing rate (e.g., [22]). In order to choose between a model specification that permits simultaneity and one that does not, one can employ the so-called Hausman specification test ([23]). If this test suggests that we should not reject the null hypothesis that $\ln C C_{n t}$ is an exogenous variable in the learning equation, we can use instrumental variable techniques to correct for endogeneity. Specifically, we can regress $\ln C C_{n t}$ on a set of variables considered exogenous to $\ln C C_{n t}$, and then employ the fitted values from this first regression as instruments in place of $\ln C C_{n t}$ in Eqs. (2) and (3). In this paper, we compare the results obtained by acknowledging endogeneity to those where simple OLS estimation procedures have been used.

Our final methodological issue concerns the presence of so-called omitted variable bias. From econometric theory we learn that if an independent variable whose true regression coefficient is nonzero is excluded from the model, the estimated values of all the regression coefficients will be biased unless the excluded variable is uncorrelated with every included variable [24]. In the case of the learning curve model this could be a real problem since costs clearly are influenced by other variables than cumulative capacity, most notably input prices and scale effects. ${ }^{7}$ In order to illustrate the potential importance of this problem, it is useful to see how one can integrate technology learning into a coherent microeconomic framework. In Section 2.2, we therefore integrate the learning curve model in Eq. (3) with the Cobb-Douglas cost function. This permits us to identify under what conditions the traditional learning curve (as outlined in Eq. (1)) is consistent with standard assumptions in neoclassical cost theory, and analyze the impact of leaving out important explanatory variables (e.g., input prices, scale effects, etc.) in the learning models.

\footnotetext{
${ }^{6}$ See also Söderholm and Klaassen [19], who employ the same dataset as that employed here and develop a simultaneous diffusion-innovation model for European wind power.

${ }^{7}$ In many learning curve studies model performance is only evaluated by checking the $t$-statistics for each coefficient and the values of the $R^{2}$ measures (e.g., [11]). However, even if the $R^{2}$ is close to one (1) and all coefficients are statistically significant, omitted variable bias may still pose a problem.
} 


\subsection{Deriving the learning curve from a Cobb-Douglas cost function}

We here follow Berndt [24] and Isoard and Soria [25] and derive the learning curve model from a Cobb-Douglas cost function. This means that for our purposes the current unit cost of wind power capacity in country $n$ during time period $t, C_{n t}^{C}$, is specified as:

$$
C_{n t}^{C}=\frac{1}{Q_{n t}}\left(k Q_{n t}^{1 / r} \prod_{i=1}^{M} P_{n t i}^{\delta_{i} / r}\right)=k Q_{n t}^{[(1-r) / r]} \prod_{i=1}^{M} P_{n t i}^{\delta_{i} / r},
$$

where

$$
k=r\left[A_{n t} \prod_{i=1}^{M} \delta_{i}^{\delta_{i}}\right]^{-1 / r} .
$$

$Q_{n t}$ is the level of wind-generated electricity output, $P_{n t i}$ are the prices $(i=1, \ldots, M)$, of the $M$ inputs required to produce and operate wind turbines (e.g., labor, energy, materials etc.), and $r$ is the returns-to-scale parameter which in turn equals the sum of the exponents so that

$$
r=\sum_{i=1}^{M} \delta_{i}
$$

The constraint in Eq. (5) ensures that the cost function is homogenous of degree one in input prices. That is, for a given output level, the unit cost doubles if all input prices double. Finally, $A_{n t}$ reflect advances in the state of knowledge.

Following the learning curve literature we can now assume that the state of knowledge in country $i$ at time period $t$ depends on learning-by-doing effects as expressed by the cumulative installed capacity of windmills up to time period $t, C C_{n t}$. However, we also build on Klaassen et al. [18] and extend this traditional learning curve concept by considering cumulative R\&D expenses on wind energy in the model. Specifically, we acknowledge that R\&D support adds to what might be referred to as the R\&D-based 'knowledge stock', and this we define as

$$
K_{n t}=(1-\gamma) K_{n(t-1)}+\mathrm{RD}_{n(t-x)},
$$

where $K_{n t}$ is the R\&D-based knowledge stock in country $n$ and time period $t, \mathrm{RD}_{t}$ are the annual R\&D expenditures, $x$ is the number of years it takes before R\&D expenditures add to the knowledge stock, and $\gamma$ is the annual depreciation rate of the knowledge stock $(0 \leqslant \gamma \leqslant 1)$. Thus, this formulation takes into account the notions that: (a) R\&D support does not have an instantaneous effect on innovation, but will only lead to tangible results after some years time; and (b) knowledge depreciates in the sense that the effect of past R\&D expenses gradually becomes outdated [26]. Due to limited data availability the analysis only makes use of data on public R\&D support towards wind power. The introduction of private $R \& D$ in the learning is clearly an important task for future research efforts, but this represents also a methodological challenge since R\&D activities undertaken by private firms normally are more applied (and are thus also associated with shorter time lags, $x$ ). However, with the inclusion of both private and public R\&D knowledge stocks there would exist a clear risk of double-counting; public R\&D support can be used to promote private companies to conduct applied research and run 
demonstration projects. Moreover, in the empirical analysis we employ own-country government R\&D in the knowledge stock, and no account is thus taken of international knowledge spillovers although these could clearly prove important in practice.

By drawing on the extended learning curve concept we can now define the state of knowledge as

$$
A_{n t}=C C_{n t}^{-\delta_{\mathrm{L}}} K_{n t}^{-\delta_{K}},
$$

where $\delta_{\mathrm{L}}$ is the traditional learning-by-doing elasticity, and where we refer to $\delta_{K}$ as the learning-by-searching elasticity. Substituting Eq. (7) into Eq. (4) yields a modified version of the Cobb-Douglas cost function:

$$
C_{n t}^{C}=k^{\prime} C C_{n t}^{\delta_{\mathrm{L}} / r} K_{n t}^{\delta_{K} / r} Q_{n t}^{[(1-r) / r]} \prod_{i=1}^{M} P_{n t i}^{\delta_{i} / r},
$$

where

$$
k^{\prime}=r\left[\prod_{i=1}^{M} \delta_{i}^{\delta_{i}}\right]^{-1 / r} .
$$

This indicates that there are two advantages of specifying a two-factor (rather than a single-factor) learning curve. First, public R\&D support is clearly a policy relevant variable that influences innovation, and its impact can be empirically assessed. Second, the introduction of R\&D expenditures also means that omitted variable bias becomes less of a problem (i.e., the variations in costs that are due to $\mathrm{R} \& \mathrm{D}$ support are not wrongly attributed to, for instance, learning-by-doing activities). The impacts of the three input prices can be captured by the use of the GDP deflator. By assuming that the shares of the inputs in production costs are the same as those used as weights in the computation of the GDP deflator, we can effectively remove the price terms from Eq. (8) by considering real (rather than current) unit costs of wind power capacity, $C_{n t}^{R}$ [24]. We obtain

$$
C_{n t}^{R}=k^{\prime} C C_{n t}^{\delta_{\mathrm{L}} / r} K_{n t}^{\delta_{K} / r} Q_{n t}^{[(1-r) / r]},
$$

where $k^{\prime}$ is defined as in Eq. (8). This shows thus that only in the case where the overall impact of the input prices can be assumed to be reflected in the GDP deflator we can remove price observations from the cost function without introducing omitted variable bias in the model. Moreover, by taking natural logarithms and introducing the following definitions: $\beta_{1}=\delta_{\mathrm{L}} / r, \beta_{2}=\delta_{K} / r, \beta_{0}=\ln k^{\prime}$ and $\beta_{3}=[(1-r) / r]$, we obtain an econometric specification of the Cobb-Douglas cost function in Eq. (9) so that

$$
\ln C_{n t}=\beta_{0}+\beta_{1} \ln C C_{n t}+\beta_{2} \ln K_{n t}+\beta_{3} \ln Q_{n t},
$$

where $\beta_{0}, \beta_{1}, \beta_{2}$ and $\beta_{3}$ are parameters to be estimated. From the parameter estimates one can easily derive the returns-to-scale parameter, $r$, and the two learning curve elasticities, $\delta_{\mathrm{L}}$ and $\delta_{K}$. We have

$$
r=\frac{1}{\left(1+\beta_{3}\right)}, \delta_{\mathrm{L}}=\beta_{1} r=\frac{\beta_{1}}{\left(1+\beta_{3}\right)} \text { and } \delta_{K}=\beta_{2} r=\frac{\beta_{2}}{\left(1+\beta_{3}\right)} .
$$


Eq. (10) equals the two-factor learning curve specification in Eq. (3) with one important exception. In Eq. (10) we incorporate scale effects by including $Q_{n t}$ into the learning curve equation; only in the restrictive case of constant returns to scale (i.e., $r=1$ and $\beta_{3}=0$ ), Eq. (10) collapses to Eq. (3), and no omitted variable bias in the latter model will be present. If not, however, the leaving out of scale effects will cause bias in the parameter estimates, and one can easily determine the direction if this bias. For instance, in the case of increasing returns to scale (i.e., $r>1$ and $\beta_{3}<0$ ), estimation of the learning curve in Eq. (3) yields a higher estimate of the learning rates than if one includes the output variable [24]. Similarly, if returns to scale are negative the learning rate estimates obtained by estimating Eq. (3) will be biased downwards. In the empirical section we therefore include current output as an explanatory variable and compare this to model specifications (implicitly) assuming constant returns to scale.

Finally, we also add a fourth independent variable to the learning equation in Eq. (10), namely the feed-in price, $P_{n t}^{\mathrm{F}}$ (and the corresponding coefficient, $\beta_{4}$ ). This is the price windmill owners receive for the wind power generated and it includes state price support (per $\mathrm{kWh}$ ). This inclusion captures the following potentially important relationships. First, a high feed-in price will induce wind energy generators to use high-cost sites with, for instance, poor wind conditions or expensive grid connections. As a result the average investment cost in country $n$ increases as the marginal revenue of producing wind generated electricity is raised. This corresponds to developments in the mining industry where a soar in mineral prices (ceteris paribus) induces high-cost mines to come into operation (e.g., [27]). Second, if feed-in prices increase, and the competition with other energy sources thus becomes less intense, innovation activities aimed at reducing costs will be less attractive on the part of the windmill owner.

\section{Data and model estimation issues}

\subsection{Data descriptive and sources}

In this paper, we make use of and extend the dataset employed in Klaassen et al. [18], who focus solely on technology learning in the wind power sectors in three European countries. We employ pooled annual time series data over four European countries: Denmark (1986-1999), Germany (1990-1999), Spain (1990-1999), and the United Kingdom (1991-2000). Following the above, the data used to estimate the different learning curve models include: (a) the cumulative capacity of windmills (MW); (b) the feedin price for electricity produced by windmills (US cents per kWh); (d) windmill investment costs (US\$ per kW); (e) public R\&D support for wind energy (1000 US\$); and windgenerated electricity production (Mtoe). All prices and costs have been deflated to 1998 prices. Data on wind-generated power generation and the cumulative capacity of windmills, respectively, are available from the International Energy Agency's (IEA) Electricity Information. The prices received by wind producers have been drawn from Ibenholt [12] (Denmark, Germany, and the UK), and for Spain from the National Energy Commission in Spain (www.cne.es).

The investment cost data used here represent averages of various projects (with the exception of the UK 1992 observation, which is only based on one project), and are drawn from ISET [28], Durstewitz [29] and Milborrow [30]. In contrast to most other estimates of windmill investment costs our data cover all investment costs items such as grid 


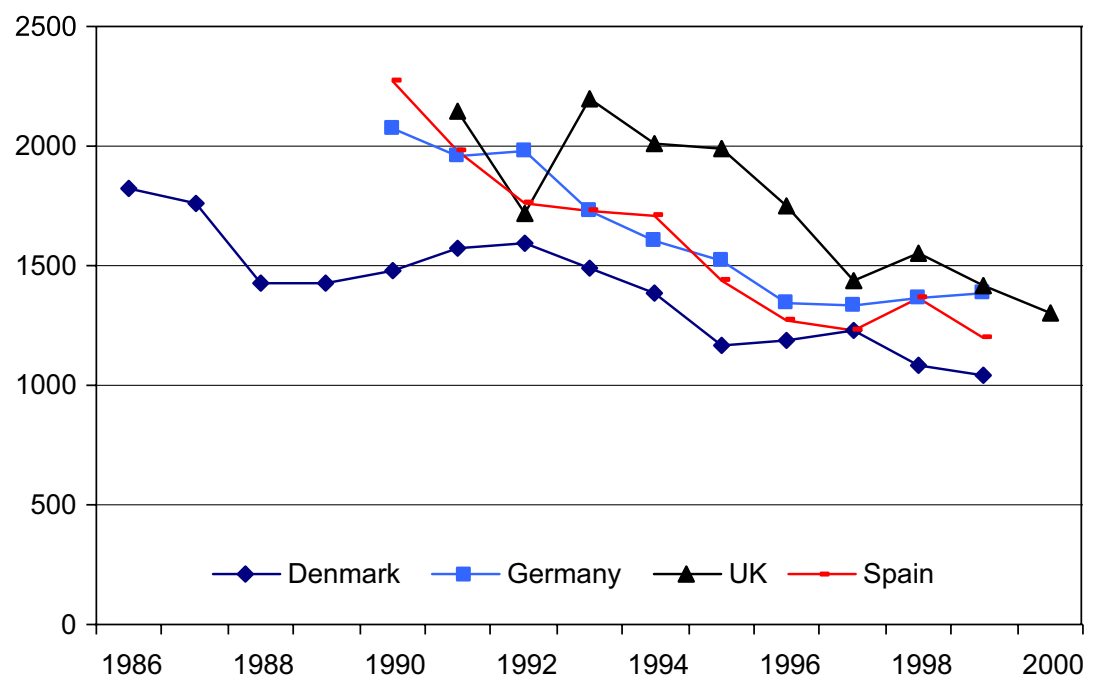

Fig. 1. Wind power investment costs, US\$ per kW (1998 prices).

connections, foundations, electrical connection and not only the costs of the wind turbine. This is important since the non-turbine part of the investment costs may amount to as much as $10-40 \%$ of the total $[31,32]$.

Annual public wind R\&D expenditure data from the International Energy Agency's online database (www.sourceoecd.org) were used to construct the knowledge stock variable. To pursue this assumptions are needed on the time lag between $R \& D$ expenditures and their addition to the knowledge stock as well as the depreciation rate of the knowledge stock. Klaassen et al. [18] survey previous studies, and based on these they suggest a time lag of 2 years and a depreciation rate of $3 \%$. These are also the assumptions employed in this paper. The IEA provides public R\&D data for wind power starting in 1974. In this year the respective national R\&D expenses were virtually (but not entirely) zero. These low figures represent our initial conditions when constructing the R\&D-based knowledge stock. For instance, the knowledge stock reported in 1990 for a specific country is a function of the cumulative $R \& D$ expenses during the time period 1974-1987 and with a depreciation rate of 3\% attached to the stock.

Figs. 1-4 show the time development of some of the key variables used in the empirical analysis. The investment costs displayed in Fig. 1 illustrate that over the relevant time period costs for investing in new wind mills have almost halved, albeit not continuously. On average, costs have been lower in Denmark, especially if compared to those prevailing in the UK. The differences in cost levels across the four countries are not only related to country-specific factors, but also reflect differences in the average size of the wind turbines installed. Fig. 2 shows the development of wind power capacity over time. Denmark has since 1986 experienced a consistent increase in wind power capacity, but more recently the capacity developments in Germany and Spain have been significant as well. From 1994, German wind power capacity exceeded Danish capacity, and Germany is today the largest producer of wind electricity worldwide. The corresponding development in the UK was much more modest during the studied time period. Fig. 3 shows the results from the construction of the R\&D-based knowledge stock. This stock increased consistently in 


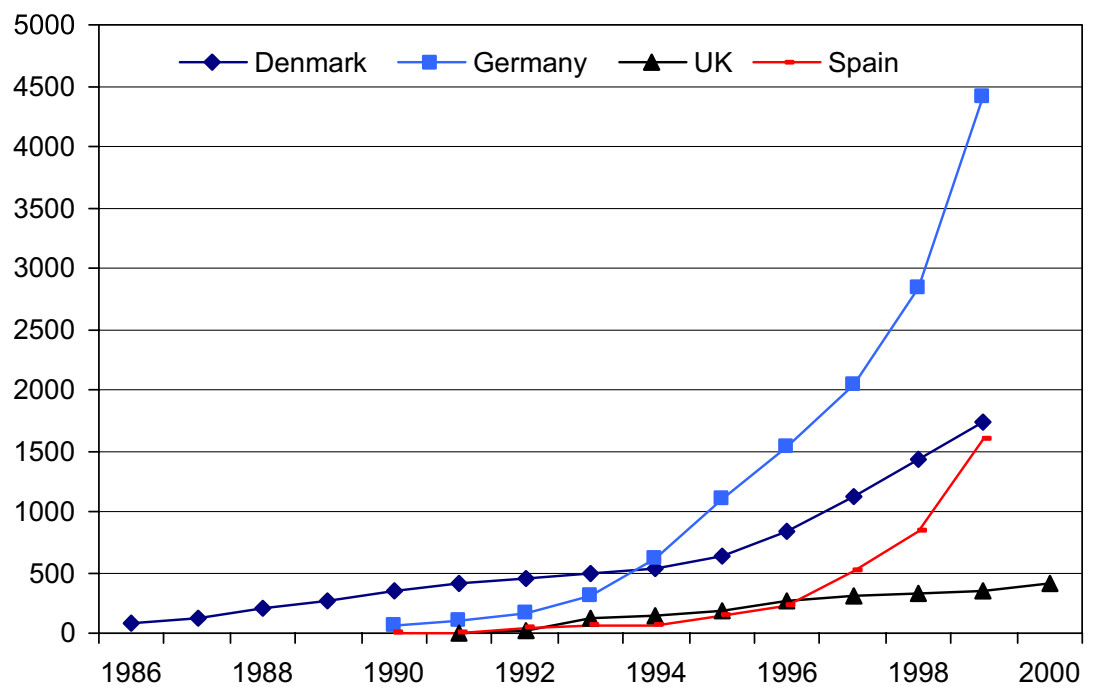

Fig. 2. Installed wind power capacity (MW).

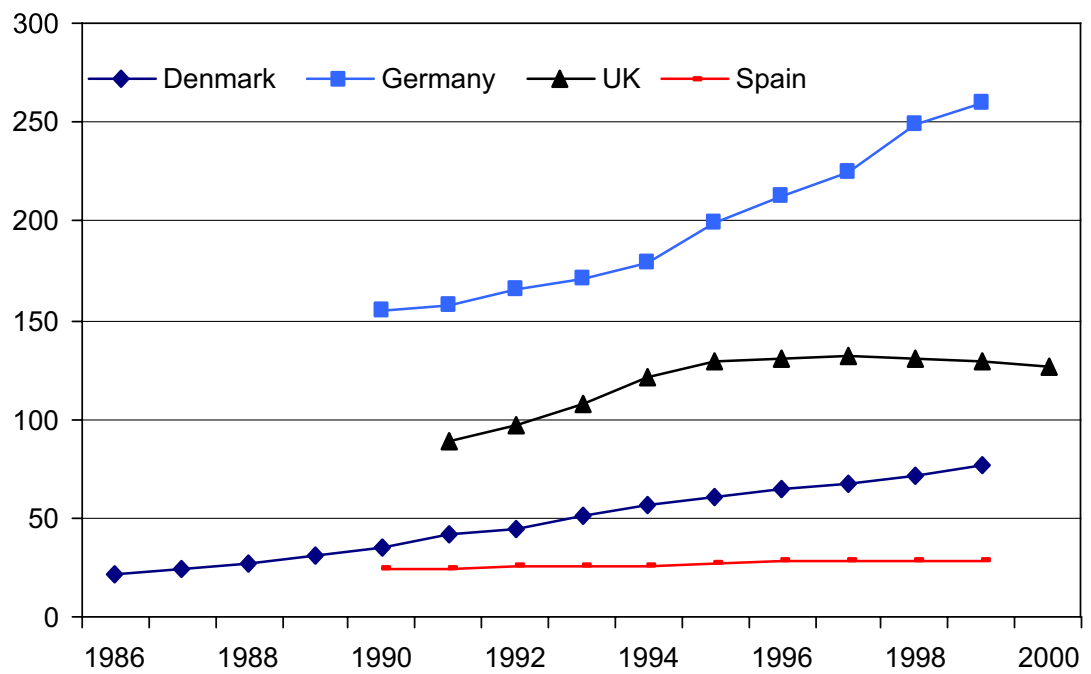

Fig. 3. Public R\&D knowledge stock, US\$ million (1998 prices).

Denmark over the time period and even more so in Germany. ${ }^{8}$ The decline in the UK stock after 1997 reflects the effect of rather sharp reductions in R\&D expenses during the early 1990s; the depletion effect of old knowledge overweighs the creation of the new knowledge created in the more recent years. In Spain, the public R\&D expenses are comparatively low and the knowledge stock depicts a rather modest increase during the 1990s. Finally, Fig. 4 shows the development of the electricity prices received by wind producers in the respective

\footnotetext{
${ }^{8}$ It is worth noting, however, that public R\&D expenses in Germany fell in the late 1990s, but due to the 3-year time lag imposed, this effect does not affect the knowledge stock displayed in Fig. 3.
} 


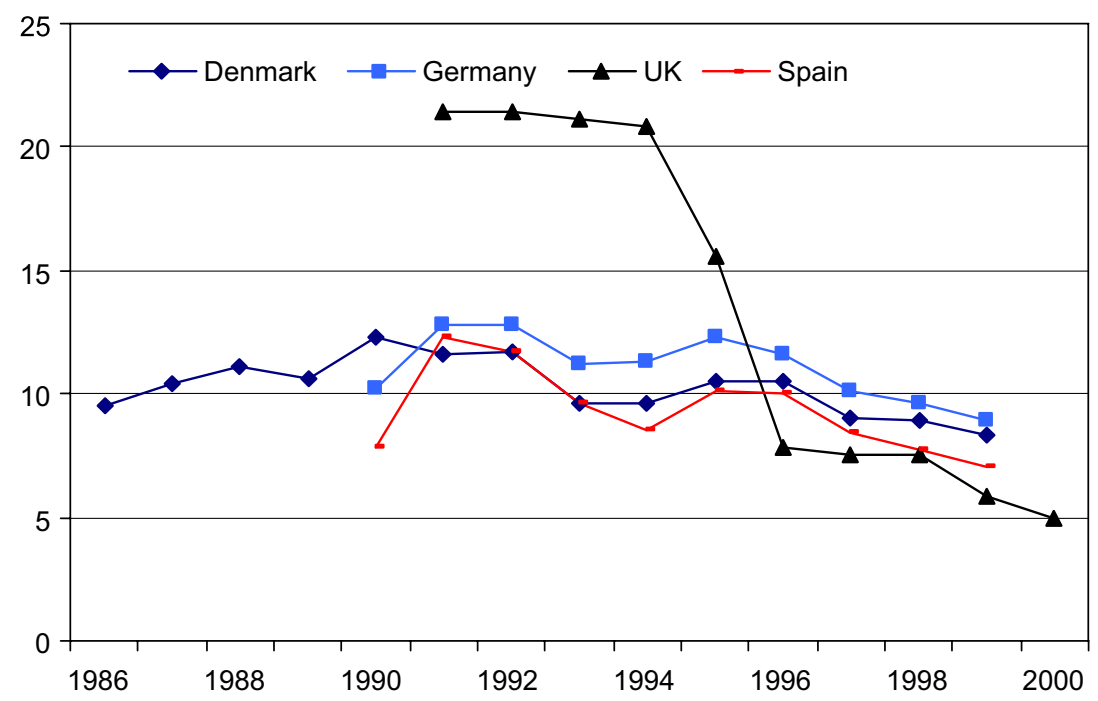

Fig. 4. Prices received by wind power producers, US cents per kWh (1998 prices).

countries. The UK is the only country that - under the time period we study - relied on a so-called competitive bidding system (the Non-Fossil Fuel Obligation). ${ }^{9}$ In this system calls for tenders are made at alternating intervals. Wind power is given a quota, and the providers of the lowest asking prices are given contracts, and the contract price received by all wind generators equals the bidding price of the marginal producer. In the fixed feed-in price systems prevailing in the other 3 countries (although with some variations) during the studied time period, a long-term minimum price is guaranteed ex ante for electricity obtained from wind power. Fig. 4 shows that with the exception of the UK the respective feed-in-prices have not changed much over time, but there is a declining trend in all countries since the mid-1990s. Among the 3 countries employing fixed feed-in tariffs Germany has generally had the highest levels and Spain the lowest.

\subsection{Econometric issues}

In estimating the learning equation we have to consider how to pool the panel dataset. We assume that the learning curve equations have an additive error structure, and we decompose this the error term, $\varepsilon_{n t}$, into two components so that

$$
\varepsilon_{n t}=\lambda_{n}+v_{n t},
$$

where $\lambda_{n}$ is the country-specific effects, while $v_{\mathrm{nt}}$ is the remainder stochastic disturbance terms. The country-specific errors may be interpreted as unobserved fundamental differences in windmill investment costs across the 4 countries. These may include geographic differences such as wind conditions and institutional arrangements related to, for instance, territorial planning and permitting procedures. We assume that these

\footnotetext{
${ }^{9}$ In 2002, the Non-Fossil Fuel Obligation was replaced by the so-called Renewable Obligation system, which is a tradable renewable certificate system.
} 
differences are fixed over time for a given country, and we can then eliminate the countryspecific components by introducing dummy variables for $N-1$ of the countries. This approach is referred to as the fixed-effects model and it overcomes the bias in the estimation results that can occur in the presence of unobserved country effects that are correlated with the regressors (e.g., [33]). It implies that the parameter estimates will be based on the time-series variations in the data sample. The remaining disturbance term, $v_{\mathrm{nt}}$, is assumed to be normally distributed with zero mean and constant variance.

As was noted above both underlying theory and intuition suggest that cumulative capacity (the learning-by-doing indicator) could be viewed as being endogenous. We also need to consider the possibility that the feed-in price is endogenous. The feed-in price is likely to be revised downwards as wind power investments costs fall, since it then is less need for policy support. In order to test for endogeneity, we employed the Hausman specification test ([23]), and in those cases where the test indicated endogeneity, this problem of simultaneity was solved by the use of instrumental variables (see further Section 4). All regressions were performed in the statistical software Limdep.

\section{Empirical comparisons of learning curve specifications}

The different specifications of the learning curve models to be compared empirically are presented in Table 1. Models I-III all build on the traditional learning curve concept in which investment cost is explained by cumulative capacity, but they differ with respect to variable definitions and use of data sample. In model I, a traditional learning curve based on all annual observations is estimated, while in model II we estimate the same equation but after having removed all observations prior to 1992 (a total of 11 observations). It is not entirely clear whether to expect that the learning rates based on the full sample compared to the corresponding estimates for the more recent (and shorter) sample would differ. One reason, though, why one could expect to obtain lower learning rates for the full sample (including the early years) is that as a technology matures the degree of competition in the input factor markets becomes stronger and as a result prices fall (e.g., [15]). Clearly this is a market power issue and not an innovation impact, but since we do not explicitly

Table 1

Different learning curve specifications

\begin{tabular}{lll}
\hline Model & Estimated learning equation & Comments \\
\hline I & $\ln C_{n t}=\ln \beta_{0}+\beta_{1} \ln C C_{n t}+\varepsilon_{n t}$ & Traditional learning curve (LC) \\
II & $\ln C_{n t}=\ln \beta_{0}+\beta_{1} \ln C C_{n t}+\varepsilon_{n t}$ & LC (1992-) \\
III & $\ln C_{n t}=\ln \beta_{0}+\beta_{1} \ln C Q_{n t}+\varepsilon_{n t}$ & LC with alternative capacity measure \\
IV & $\ln C_{n t}=\ln \beta_{0}+\beta_{1} \ln C C_{n t}+\beta_{2} \ln Q_{n t}+\varepsilon_{n t}$ & LC+ scale effects \\
V & $\ln C_{n t}=\ln \beta_{0}+\beta_{1} \ln C C_{n t}+\beta_{2} \ln R D_{n t}+\varepsilon_{n t}$ & Two-factor learning curve (2FLC) \\
VI & $\ln C_{n t}=\ln \beta_{0}+\beta_{1} \ln C C_{n t}+\beta_{2} \ln K_{n t}+\varepsilon_{n t}$ & 2FLC with knowledge stock \\
VII & $\ln C_{n t}=\ln \beta_{0}+\beta_{1} \ln C C_{n t}+\beta_{2} \ln K_{n t}+\beta_{3} \ln Q_{n t}+\varepsilon_{n t}$ & 2FLC+scale effects \\
VIII & $\ln C_{n t}=\ln \beta_{0}+\beta_{1} \ln C C_{n t}+\beta_{2} \ln K_{n t}+\beta_{3} \ln Q_{n t}+\beta_{4} \ln P_{n t}^{\mathrm{F}}+\varepsilon_{n t}$ & 2FLC+scale effects \& feed-in price \\
IX & $\ln C_{n t}=\ln \beta_{0}+\beta_{1} \ln C C h a t_{n t}+\varepsilon_{n t}$ & I corrected for endogeneity in CC \\
X & $\ln C_{n t}=\ln \beta_{0}+\beta_{1} \ln C C h a t_{n t}+\beta_{2} \ln K_{n t}+\varepsilon_{n t}$ & VI corrected for endogeneity in CC \\
XI & $\ln C_{n t}=\ln \beta_{0}+\beta_{1} \ln C C h a t_{n t}+\beta_{2} \ln K_{n t}+\beta_{3} \ln Q_{n t}+\varepsilon_{n t}$ & VII corrected for endogeneity in CC \\
XII & $\ln C_{n t}=\ln \beta_{0}+\beta_{1} \ln C C_{n t}+\beta_{2} \ln K_{n t}+\beta_{3} \ln Q_{n t}+\beta_{4} \ln P h a t t_{n t}^{\mathrm{F}}+\varepsilon_{n t}$ & VIII corrected for endogeneity in $P^{\mathrm{F}}$ \\
\hline
\end{tabular}


acknowledge input prices in our model specifications any observed cost decreases will be attributed to learning (rather than price) impacts. In model III, we use a different proxy for learning-by-doing and substitute cumulative wind production ( $\ln C Q_{n t}$ measured in $\mathrm{MWh}$ ) for cumulative capacity (MW).

Models IV-VIII are designed to consider various versions of omitted variable bias. In model IV we extend the traditional learning curve equation (model I) by incorporating also scale effects through the introduction of the contemporaneous wind generation level. ${ }^{10}$ Models V and VI represent different versions of the two-factor learning curve, where model $\mathrm{V}$ uses cumulative $\mathrm{R} \& \mathrm{D}$ expenditures $\left(\ln \mathrm{RD}_{n t}\right)$ with no account taken of knowledge depreciation and time lags, while model VI-following Klaassen et al. [18] and Söderholm and Klaassen [19] - includes the R\&D based knowledge stock (thus with time lags and depreciation included) $\left(\ln K_{n t}\right)$. These models permit the estimation of learning-bysearching rates. In models VII and VIII we extend this two-factor learning curve further by adding also scale effects (model VII) and the impact of policy through feed-in prices (model VIII).

In model specifications IX-XII, we acknowledge the fact that cumulative capacity and also the feed-in price can be considered endogenous and thus simultaneously determined with investment costs. The Hausman test suggested that for models I, VI and VII we could reject the null hypothesis that $\ln C C_{n t}$ is an exogenous variable. For model VIII only $\ln P_{n t}^{\mathrm{F}}$ was found to be endogenously determined. The simultaneity problem was solved using instrumental variables where $\ln C C_{n t}$ and $\ln P_{n t}^{\mathrm{F}}$ were regressed on a set of variables (first lag as well as contemporaneous values) considered exogenous (e.g., electricity prices, age structure of existing coal-fired power plants, coal prices, etc.). ${ }^{11}$ The fitted values of $\ln C C_{n t}$ (models IX-XII) and $\ln P_{n t}^{\mathrm{F}}$ (model XII), respectively, were then employed in the different learning equations. Finally, as was noted above (Section 2.1), in all models I-XII we also include a simple time trend, $T$, to test the robustness of the learning parameters obtained.

The parameter estimation results for the different learning curve models with no time trend included are presented in Table 2 together with calculated learning-by-doing andwhere applicable - learning-by-searching rates. Overall all models display relatively good fits with $R^{2}$-values ranging from 0.67 to 0.97 . However, the estimated learning-by-doing rates and learning-by-searching rates vary considerably across the different specifications of the learning curve.

When comparing models I and II we note that the estimated learning-by-doing rate is substantially higher in the shorter (and more recent) time period. The choice of dataset appears to have a significant effect on the results, and as was noted above these results are consistent with the hypothesis that the suppliers of wind turbines have had significant market power during the early diffusion phase of the technology. This leads to limited reported cost reductions for the initiation phase, but as competition between suppliers intensify, input prices are (ceteris paribus) lowered. Employing an alternative proxy for learning - cumulative wind generation - produces a higher learning-by-doing rate (than in the case where learning is measured through cumulative capacity). Thus, overall the above

\footnotetext{
${ }^{10}$ Clearly, this is a rather rough indicator of returns-to-scale effects, but the limited data availability has prevented us from including, for instance, the sizes of the turbines installed over the entire time period studied.

${ }^{11}$ For the countries included in this study, coal is overall by far the most important fuel in existing power generation mixes, and wind power capacity will increase with higher coal prices. An increase in the coal price makes existing coal-fired capacity less valuable as it implies fewer incentives to extend the lives and increase the utilization of existing coal plants.
} 
Table 2

Parameter estimates for the different learning model specifications (no time trend included)

\begin{tabular}{|c|c|c|c|c|c|c|c|c|c|c|c|c|}
\hline $\begin{array}{l}\text { Coefficient ( } t- \\
\text { statistic) }\end{array}$ & Model I & Model II & Model III & Model IV & Model V & Model VI & Model VII & Model VIII & Model IX & Model X & Model XI & Model XII \\
\hline$\beta_{0}(\mathrm{DK})$ & $7.68 * *(115.21)$ & $7.97 * *(56.96)$ & $7.11 * *(246.24)$ & $7.18^{* *}(44.56)$ & $7.87 * *(86.88)$ & $8.56^{* *}(35.37)$ & $8.01 * *(19.69)$ & $7.91 * *(20.75)$ & $7.95 * *(286.08)$ & $7.91 * *(73.77)$ & $7.84 * *(55.72)$ & $7.75^{* *}(23.95)$ \\
\hline$\beta_{0}(\mathrm{DE})$ & $7.85 * *(108.48)$ & $8.19^{* *}(56.47)$ & $7.22 * *(209.48)$ & $7.35 * *(44.49)$ & $8.00 * *(93.45)$ & $9.11^{* *}(26.62)$ & $8.44 * *(16.15)$ & $8.37 * *(17.14)$ & $8.13 * *(272.05)$ & $8.07 * *(52.06)$ & $8.00 * *(42.60)$ & $8.25 * *(20.01)$ \\
\hline$\beta_{0}(\mathrm{UK})$ & $7.81 * *(130.02)$ & $8.08 * *(72.44)$ & $7.20^{* *}(184.62)$ & $7.29 * *(44.11)$ & $8.07 * *(75.20)$ & $8.96^{* *}(28.59)$ & $8.32 * *(16.82)$ & $8.25 * *(17.84)$ & $8.02 * *(331.92)$ & $7.97 * *(55.42)$ & $7.90 * *(44.67)$ & $8.12 * *(20.81)$ \\
\hline$\beta_{0}(\mathrm{ES})$ & $7.65 * *(142.00)$ & $7.94 * *(69.37)$ & $7.06 * *(169.21)$ & $7.13 * *(44.18)$ & $7.73 * *(135.02)$ & $8.43 * *(29.23)$ & $7.90 * *(20.69)$ & $7.83 * *(21.93)$ & $7.82 * *(368.77)$ & $7.78 * *(80.03)$ & $7.72 * *(58.86)$ & $7.69 * *(25.43)$ \\
\hline$\beta_{i}\left(\ln C C_{n t}\right)$ & $-0.07 * *(-7.66)$ & $-0.12 * *(-6.16)$ & - & $-0.03(-1.55)$ & $-0.04 * *(-3.13)$ & $-0.06 * *(-5.85)$ & $-0.03 *(-2.09)$ & $-0.05^{* *}(-2.88)$ & - & - & - & $-0.05^{* *}(-3.72)$ \\
\hline$\beta_{i}\left(\ln \mathrm{RD}_{n t}\right)$ & - & - & - & - & $-0.11 * *(-2.80)$ & - & - & - & - & - & - & - \\
\hline$\beta_{i}\left(\ln K_{n t}\right)$ & - & - & - & - & - & $-0.26^{* *}(-3.72)$ & $-0.18 *(-2.20)$ & $-0.20 *(-2.64)$ & - & $0.01(0.38)$ & $0.02(0.54)$ & $-0.24 * *(-3.66)$ \\
\hline$\beta_{i}\left(\ln Q_{n t}\right)$ & - & - & - & $-0.78 * *(-3.34)$ & - & - & $-0.04(-1.65)$ & $-0.01(-0.37)$ & - & - & $-0.01(-0.69)$ & $0.01(0.50)$ \\
\hline$\beta_{i}\left(\ln C Q_{n t}\right)$ & - & - & $-0.09 * *(-10.39)$ & - & - & - & - & - & - & - & - & - \\
\hline$\beta_{i}\left(\ln P_{n t}^{\mathrm{F}}\right)$ & - & - & - & - & - & - & - & $0.15 *(2.57)$ & - & - & - & - \\
\hline$\beta_{i}\left(\ln \hat{C} C_{n t}\right)$ & - & - & - & - & - & - & - & - & $-0.12 * *(-27.89$ & $-0.12 * *(-20.16)$ & $-0.11^{* *}(-14.26)$ & - \\
\hline$\beta_{i}\left(\ln \hat{P}_{n t}^{\mathrm{F}}\right)$ & - & - & - & - & - & - & - & - & - & - & - & $0.31 * *(4.91)$ \\
\hline$R^{2}$ (adjusted) & $0.67(0.64)$ & $0.72(0.67)$ & $0.78(0.76)$ & $0.75(0.71)$ & $0.73(0.69)$ & $0.76(0.73)$ & $0.78(0.74)$ & $0.81(0.77)$ & $0.96(0.96)$ & $0.96(0.96)$ & $0.96(0.96)$ & $0.87(0.84)$ \\
\hline$F$-statistic & 19.90 & 17.61 & 34.89 & 22.31 & 20.26 & 23.93 & 21.29 & 21.94 & 238.32 & 186.48 & 153.37 & 33.09 \\
\hline Observations & 44 & 33 & 44 & 44 & 44 & 44 & 44 & 44 & 44 & 44 & 44 & 44 \\
\hline $\begin{array}{l}\text { Learning-by- } \\
\text { doing rate }(\%)\end{array}$ & 4.97 & 8.25 & 5.84 & 1.77 & 2.97 & 3.80 & 2.33 & 3.11 & 7.76 & 7.85 & 7.62 & 3.33 \\
\hline $\begin{array}{l}\text { Learning-by- } \\
\text { searching rate } \\
(\%)\end{array}$ & - & - & - & - & 7.08 & 16.43 & 11.85 & 13.24 & - & -0.88 & -1.32 & 15.41 \\
\hline
\end{tabular}


results indicate that the relatively simplistic traditional learning curve equation is data and definition sensitive and that results from these types of estimations need to be interpreted with some care.

Adding scale effects to the basic learning curve model, as in model IV, also significantly affects results. The parameter estimate for $\ln Q_{n t}$ is statistically significant at the one percent level while the estimate for $\ln C C_{n t}$ becomes statistically significant only at the $15 \%$ level. The negative sign of the coefficient for $\ln Q_{n t}$ implies that wind power developments in the four countries are exhibiting increasing returns to scale. As was noted in the theoretical discussion, failing to account for this scale effect generates a positive bias in the learning rate estimate. Our results show that in the absence of a returns-to-scale parameter (model I) the learning-by-doing rate equals almost $5 \%$, while it is only $1.8 \%$ when the scale effect is introduced (model IV).

The results of the two-factor learning curve estimations show that the choice of R\&D measure marginally affects the learning-by-doing rate, which ranges from $3.0 \%$ to $3.8 \%$ in models V and VI. With respect to the learning-by-searching rates the model specification including the R\&D-based knowledge stock, however, produces a more than twice as high estimate than the model including cumulative R\&D expenses. Adding additional variables, as in models VII and VIII, also changes the results. Still, the $\ln Q_{n t}$ parameters are statistically insignificant in both model VII and model VIII, indicating that scale economies do not significantly lower costs (and no bias in the results will appear from omitting scale effects). The $\ln P_{n t}^{\mathrm{F}}$ parameter in model VIII is statistically significant and positive implying that an increase in the feed-in price will lead to higher (average) investment costs.

In the models where we corrected for endogeneity in $\ln C C_{n t}$, models IX-XI, it is first of all worth noting that the estimated learning-by-doing rates are very stable across specifications (they range from $7.6 \%$ to $7.8 \%$ ), but they are substantially higher than those generated by the corresponding models assuming exogeneity in $\ln C C_{n t}$ (i.e., models I, VI and VII). In contrast, the learning-by-searching rates become substantially lower and even negative. In model XII, we corrected for the endogeneity of the feed-in price variable. The results from this model are rather close to those obtained in model VIII (with exogenous feed-in prices); the learning-by-doing rates are $3.1 \%$ and $3.4 \%$, respectively, while the corresponding learning-by-searching rates are $13.2 \%$ and $18.2 \%$. It is difficult to conclude what causes these differences in results between model specifications, but it is clear that simultaneity should be carefully considered in estimating learning curves.

Table 3 repeats the model estimations I-XII but with a simple time trend added to each of the regressions. We also introduce an additional model (model 0), in which (apart from the country intercepts) the time trend replaces $\ln C C_{n t}$ (i.e., $\ln C_{n t}=\ln \beta_{0}+\beta_{1} \ln T+\varepsilon_{n t}$ ). The results from model 0 show that the time trend picks up a significant part of the variations in average investment costs $\left(R^{2}\right.$ equals 0.68$)$, and the estimated coefficient is highly statistically significant. This should not appear surprising since investment costs show a clear decreasing trend over time (Fig. 1). The results also show that for the traditional learning curve estimations (with only cumulative capacity included), the inclusion of the time trend implies significantly different estimates of the learning-by-doing rate. For instance, in model I the learning-by-doing rate decreases from almost 5\% to $3 \%$ as the time trend is added to the estimations, suggesting that in the absence of the time trend too much variation may be wrongly attributed to industry-specific learning-by-doing activities (rather than to exogenous technical progress). Nevertheless, in model I with a 
Table 3

Parameter estimates for the different learning model specifications (time trend included)

\begin{tabular}{|c|c|c|c|c|c|c|c|c|c|c|c|c|c|}
\hline $\begin{array}{l}\text { Coefficient }(t- \\
\text { statistics in } \\
\text { parenthese) }\end{array}$ & Model 0 & Model I & Model II & Model III & Model IV & Model V & Model VI & Model VII & Model VIII & Model IX & Model X & Model XI & Model XII \\
\hline$\beta_{0}(\mathrm{DK})$ & $7.74 * *(107.70)$ & $7.82 * *(125.19)$ & $7.39 * *(37.39)$ & $7.27 * *(60.50)$ & $7.58^{* *}(37.62)$ & $7.75^{* *}(88.34)$ & $7.46^{* *}(13.45)$ & $7.18^{* *}(12.11)$ & $7.12^{* *}(12.91)$ & $7.95 * *(280.01)$ & $7.61^{* *}(35.46)$ & $7.61 * *(34.71)$ & $6.83^{* *}(15.30)$ \\
\hline$\beta_{0}(\mathrm{DE})$ & $8.00 * *(91.57)$ & $8.05 * *(109.23)$ & $7.58 * *(36.53)$ & $7.42 * *(50.44)$ & $7.79 * *(35.97)$ & $8.03 * *(104.94)$ & $7.54 * *(9.53)$ & $7.23 * *(8.79)$ & $7.21 * *(9.44)$ & $8.14 * *(253.79)$ & $7.65^{* *}(25.03)$ & $7.65^{* *}(24.67)$ & $6.91 * *(11.23)$ \\
\hline$\beta_{0}(\mathrm{UK})$ & $8.10^{* *}(89.07)$ & $8.07 * *(105.69)$ & $7.70 * *(54.84)$ & $7.43 * *(44.59)$ & $7.80 * *(33.57)$ & $8.01 * *(82.53)$ & $7.63 * *(11.23)$ & $7.31 * *(10.14)$ & $7.28 * *(10.87)$ & $8.03 * *(245.94)$ & $7.61 * *(28.95)$ & $7.61 * *(28.42)$ & $7.01 * *(12.98)$ \\
\hline$\beta_{0}(\mathrm{ES})$ & $7.97 * *(91.23)$ & $7.91 * *(106.44)$ & $7.94 * *(69.37)$ & $7.29 * *(43.45)$ & $7.64 * *(33.18)$ & $7.96 * *(82.53)$ & $7.65^{* *}(18.60)$ & $7.34 * *(15.51)$ & $7.30 * *(16.59)$ & $7.83 * *(242.50)$ & $7.58 * *(47.44)$ & $7.57 * *(45.06)$ & $7.08 * *(19.88)$ \\
\hline$\beta_{i}\left(\ln C C_{n t}\right)$ & - & $-0.04^{* *}(-4.25)$ & $0.00005(0.01)$ & - & $-0.03(-1.94)$ & $-0.05^{* *}(-4.07)$ & $-0.04 * *(-3.52)$ & $-0.03(-1.57)$ & $-0.04 *(-2.36)$ & - & - & - & $-0.04^{* *}(-3.21)$ \\
\hline$\beta_{i}\left(\ln \mathrm{RD}_{n t}\right)$ & - & - & - & - & - & $0.06(-1.03)$ & - & - & - & - & - & - & - \\
\hline$\beta_{i}\left(\ln K_{n t}\right)$ & - & - & - & - & - & - & $0.12(0.65)$ & $0.13(0.72)$ & $0.10(0.56)$ & - & $0.11(1.58)$ & $0.11(1.50)$ & $0.10(0.73)$ \\
\hline$\beta_{i}\left(\ln Q_{n}\right)$ & - & - & - & - & $-0.03(-1.25)$ & - & - & $-0.03(-1.27)$ & $-0.002(-0.06)$ & - & - & $-0.002(-0.19)$ & $0.02(1.09)$ \\
\hline$\beta_{i}\left(\ln C Q_{n t}\right)$ & - & - & - & $-0.07^{* *}(-4.51)$ & - & - & - & - & - & - & - & - & - \\
\hline$\beta_{i}\left(\ln P_{n t}^{\mathrm{F}}\right)$ & - & - & - & - & - & - & - & - & $0.15^{*}(2.59)$ & - & - & - & - \\
\hline$\beta_{i}\left(\ln \hat{C} C_{n t}\right)$ & - & - & - & - & - & - & - & - & - & $-0.11 * *(-16.4$ & $-0.11^{* *}(-15.8$ & $-0.11 * *(-13.37)$ & - \\
\hline$\beta_{i}\left(\ln \hat{P}_{n t}^{\mathrm{F}}\right)$ & - & - & - & - & - & - & - & - & - & - & - & - & $0.32^{* *}(5.45)$ \\
\hline$\beta_{i}\left(\ln T_{n t}\right)$ & $-0.28 * *(-7.85)$ & $-0.17^{* *}(-4.45)$ & $-0.19 * *(-3.64)$ & $-0.08(-1.41)$ & $-0.14 * *(-2.89)$ & $-0.24 * *(-3.32)$ & $-0.24 *(-2.18)$ & $-0.21(-1.88)$ & $-0.20 *(-1.93)$ & $-0.01(-0.38)$ & $-0.07(-1.58)$ & $-0.07(-1.41)$ & $-0.23^{* *}(-2.75)$ \\
\hline$R^{2}$ (adjusted) & $0.68(0.65)$ & $0.78(0.76)$ & $0.81(0.77)$ & $0.79(0.77)$ & $0.79(0.76)$ & $0.79(0.76)$ & $0.79(0.75)$ & $0.80(0.76)$ & $0.83(0.79)$ & $0.96(0.96)$ & $0.96(0.96)$ & $0.96(0.96)$ & $0.89(0.86)$ \\
\hline$F$-statistic & 20.83 & 27.56 & 22.90 & 29.01 & 23.56 & 23.17 & 22.68 & 20.00 & 21.12 & 186.50 & 161.96 & 135.21 & 35.19 \\
\hline Observations & 44 & 44 & 33 & 44 & 44 & 44 & 44 & 44 & 44 & 44 & 44 & 44 & 44 \\
\hline $\begin{array}{l}\text { Learning-by- } \\
\text { doing rate }\end{array}$ & - & $2.99 \%$ & $-0.03 \%$ & $4.65 \%$ & $2.04 \%$ & $3.49 \%$ & $2.77 \%$ & $1.77 \%$ & $2.55 \%$ & $7.62 \%$ & $7.44 \%$ & $7.39 \%$ & $2.73 \%$ \\
\hline $\begin{array}{l}\text { Learning-by- } \\
\text { searching rate }\end{array}$ & - & - & - & - & - & $-4.43 \%$ & $-8.73 \%$ & $-9.65 \%$ & $-6.90 \%$ & - & $-8.22 \%$ & $-8.03 \%$ & $-7.26 \%$ \\
\hline
\end{tabular}

${ }^{* *}$, and ${ }^{* * *}$ denote statistical significance at the 5 and $1 \%$ levels, respectively. 
time trend added the learning-by-doing impact is (although lower) still present as the learning parameter is highly statistically significant.

Interestingly, for all of the extended models IV-XII, the estimates of the learning-bydoing parameter appear fairly insensitive to the inclusion of a time trend. The biggest difference is found in model VI, in which, though, the learning-by-doing rate "only" becomes 1 percentage point lower when a time trend is added. In addition, in all but one case (model VII) the learning-by-doing parameter remains statistically significant. Instead we find that the learning-by-searching rates are very sensitive to the time trend test. All these rates actually become negative, and in neither of the relevant models we find a statistically significant learning-by-searching parameter. The time trend tends thus to pick up most of the variation previously ascribed to the R\&D-based knowledge stock, implying that the learning-by-searching estimates presented in Table 2 must be interpreted with much care.

In sum, the above results illustrate that the empirical estimates of learning rates may differ significantly across different model specifications even though the same dataset is used. The learning-by-doing rates reported in Tables 2 and 3 range from virtually $0-8 \%$. This range is overall quite significant. Learning rate estimates for other electric power technologies often range between $1 \%$ and $10 \%$ (e.g., [11]), so for the future competitiveness of wind power it makes a huge difference whether the learning-by-doing impact on cost reduction is, say, $2 \%$ or $8 \%$. This reinforces the importance of addressing the kind of empirical measurement problems analyzed in this paper.

\section{Concluding remarks}

The concept of technological learning has been widely used since its introduction in the economics literature [34], and it has gained substantial empirical support in many applications. However, while the direction of the impact of learning on costs is undisputed it remains less than clear what the size of this effect is. With the increased use of bottom-up energy models with endogenous learning it is becoming important for energy scenario analysis to get hold of reliable technology learning rates. In order to estimate learning rates we need to employ econometric methods and in this paper we have discussed and analyzed a number of important - but often neglected - econometric and theoretical issues in the empirical assessment of learning rates. The empirical analysis of learning effects in the European wind power sector illustrates that estimates of learning rates may differ significantly depending on whether or not one acknowledges these issues in the econometric models, and the reported differences are high enough to have a significant impact on optimal technology choices in the electric power sector.

From the analysis in this paper it is possible to point at some general guidelines for energy analysts who need to select empirical estimates of learning rates from the empirical literature and/or who plan to estimate these themselves. First, it is important to perform some type of sensitivity analysis by, for instance, considering: (a) the impact of removing some observations from the data sample; and (b) different variable definitions. This also means that if one is to rely on previous empirical learning curve studies, it probably makes most sense to consider the results from several such studies and to make some informed judgment about the mean estimate rather than to rely on the results from one single study. It must also be emphasized that the choice of learning rate estimates as inputs in large-scale energy system models will depend on the research question posed. For instance, if energy 
technology choices and mixes represent the main outcome of the research endeavor, relative learning estimates matter. It then becomes important to investigate differences in learning rates across different technologies, and test whether these differences remain stable with the use of different model specifications and data. On the other hand, absolute estimates of learning rates become particularly important if the research task is to assess the gross cost to the economy of, for instance, the introduction of carbon dioxide emission constraints.

Second, the problem of omitted variable bias needs to be taken seriously, not only in own econometric analyses of learning curves but also in considering other's work. Scale effects should be tested for, and when relying on previous studies any evidence on scale effects should be considered when selecting learning rates. For instance, a learning curve analysis of nuclear power failing to incorporate scale effects would, ceteris paribus, result in a positive bias of the learning rate. That is, by not incorporating the likely positive returns to scale in nuclear power generation a too large part of the cost reductions would be wrongly attributed to learning effects. Similarly, it must also be assessed whether input prices have played an essential role in affecting the cost structure of the specific technology over the time period under study. Moreover, it is equally important to consider the policy impacts on innovation. The learning curve literature recognizes that policy support in the form of investment grants and feed-in tariffs is necessary to encourage technology diffusion and thus learning-by-doing. Still, the measures implemented to bring about diffusion may in them-selves affect the incentives to undertake earning activities. For instance, fixed feed-in tariffs for wind power (such as those found in Germany and Spain) may discourage competition among various renewable energy sources and therefore deter innovation; they also tend to promote the diffusion of wind mils at high-cost sites. This notion parallels the so-called Lucas critique as it is outlined in the macroeconomics literature. Lucas [35] points out that it may be a bad practice for analysts to use an estimated econometric model found suitable for one time period when attempting to predict what will happen in another period but under a different set of policy rules. Most previous learning curve studies build on the presumption that the structure of the model employed is unaffected by any policy changes over the time period considered.

Third, the issue of simultaneity in the technology learning rate estimations addresses the fact that diffusion and innovation are not independent variables. This could (and should) be tested for with the help of appropriate statistical tests. The issue of simultaneity also raises the more fundamental question of what are the most appropriate causal relationships to consider when analyzing $R \& D$ efforts, innovation and technology diffusion. The economics literature on technological change and innovation provides some guidelines but much remains to be done before we can claim to have a more detailed understanding of the technology learning process.

Finally, the time trend test illustrated above should represent an important part of the assessment of the robustness of the estimations performed. Learning curve studies for renewable energy technologies must-more or less by definition-rely on time-series data, and these data typically show a strong upward or downward trend, making it difficult to distinguish between endogenous learning activities on the one hand and exogenous technical progress on the other. Overall this also emphasizes the need for more detailed studies of the sources of technical change and learning in the renewable energy sector. 


\section{References}

[1] Grübler A, Nakicenovic N, Nordhaus WD. Technological change and the environment. Washington, DC: Resources for the Future; 2002.

[2] McVeigh J, Burtraw D, Darmstadter J, Palmer K. Winner, loser or innocent victim? Has renewable energy performed as expected? Sol Energy 2000;68(3):237-55.

[3] Messner S. Endogenized technological learning in an energy systems model. J Evolut Econ 1997;7: 291-313.

[4] Mattsson N, Wene CO. Assessing new energy technologies using an energy system model with endogenized experience curves. Int J Energy Res 1997;21:385-93.

[5] Kouvaritakis N, Soria A, Isoard S. Endogenous learning in World Post-Kyoto Scenarios: application of the POLES model under adaptive expectations. Int J Global Energy Issues 2000;14(1-4):222-48.

[6] Barreto L, Kypreos S. Endogenizing R\&D and market experience in the 'Bottom-up' Energy-systems ERIS Model. Technovation 2003;24:615-29.

[7] Berglund C, Söderholm P. Modeling technical change in energy system analysis: analyzing the introduction of learning-by-doing in bottom-up energy models. Energy Policy 2006;34:1344-56.

[8] Rasmussen TN. $\mathrm{CO}_{2}$ abatement policy with learning-by-doing in renewable energy. Resource Energy Econ 2001;23:297-325.

[9] Gritsevskyi A, Nakicenovic N. Modeling uncertainty of induced technological change. Energy Policy 2000;28:907-21.

[10] Rosendahl KE. Cost-effective environmental policy: implications of induced technological change. J Environ Econ Manage 2004;48:1099-121.

[11] McDonald A, Schrattenholzer L. Learning rates for energy technologies. Energy Policy 2000;29:255-61.

[12] Ibenholt K. Explaining learning curves for wind power. Energy Policy 2002;30:1181-9.

[13] Neij L, Andersen PD, Durstewitz M. Experience curves for wind power. Int J Energy Technol Policy 2004;2(1-2):15-32.

[14] Grenaa JS. Describing technological development with quantitative models. Energy Environ 2004;15(2): $187-200$

[15] Claeson CU, Cornland D. The economics of the combined cycle gas turbine-an experience curve analysis. Energy Policy 2002;30:309-16.

[16] Hamon C. Experience curves of photovoltaic technology. IIASA Interim Report IR-00-014. Laxenburg, Austria: International Institute for Applied Systems Analysis; 2000.

[17] Neij L. Cost dynamics of wind power. Energy 1999;24:375-89.

[18] Klaassen G, Miketa A, Larsen K, Sundqvist T. The impact of R\&D on innovation for wind energy in Denmark, Germany and the United Kingdom. Ecol Econ 2005;54:227-40.

[19] Söderholm P, Klaassen G. Wind power in Europe: a simultaneous Innovation-Diffusion Model. Environ Resource Econ 2007;36(2):163-90.

[20] Hansen JD, Jensen C, Madsen ES. The establishment of the Danish windmill industry - was it worthwhile? Rev World Econ 2003;139(2):324-47.

[21] Papineau M. An economic perspective on experience curves and dynamic economies in renewable energy technologies. Energy Policy 2005;34:422-32.

[22] Greene W. Econometric analysis. New York: MacMillan; 1993.

[23] Hausman JA. Specification tests in econometrics. Econometrica 1978;46:1251-71.

[24] Berndt ER. The practice of econometrics: classic and contemporary. New York: Addison-Wesley; 1991.

[25] Isoard S, Soria A. Technical change dynamics: evidence from the emerging renewable energy technologies. Energy Econ 2001;23:619-36.

[26] Griliches Z. R\&D and productivity: econometric results and measurement issues. In: Stoneman P, editor. Handbook of economics on innovation and technological change. Oxford: Blackwell; 1995.

[27] Berndt ER, Ellerman AD, Schennach SM, Stoker TM. Panel data analysis of US Coal productivity. J Econometr 2005;127(2):131-64.

[28] Institute for solar energy technology (ISET) European Wind Energy Information Network. Germany: Kassel; 2002 http://euwinet.iset.uni-kassel.de.

[29] Durstewitz M. Personal communication. Institut für Solare Energieversorgungs-technik (ISET), 5 October 2000.

[30] Milborrow D. Personal communication. Technical consultant to Wind Power Monthly, 11 November 2000. 
[31] Rohrig K. Personal communication. Kassel, Germany: Institute for Solar Energy Technology (ISET); 23 January 2001

[32] Varela M. Personal communication. Madrid, Spain: CIEMAT; 24 January 2001.

[33] Baltagi BH. Econometric analysis of panel data. New York: Wiley; 1995.

[34] Arrow KJ. The economic implications of learning by doing. Rev Econ Stud 1962;29:155-73.

[35] Lucas RE. Econometric policy evaluations: a critique. In: Brunner K, Meltzer AH, editors. The Phillips curve and the labor market. Amsterdam: North Holland; 1976. 